\title{
Rapid, Semi-Automated Fractionation of Freshwater Dissolved Organic Carbon Using DAX 8 (XAD 8) and XAD 4 Resins in Tandem
}

\author{
David D. Hughes*, Peter J. Holliman, Timothy Jones, Alexander J. Butler Christopher Freeman \\ Wolfson Carbon Capture Laboratory, Bangor University, Wales, UK \\ Email: david.hughes@bangor.ac.uk
}

How to cite this paper: Hughes, D.D., Holliman, P.J., Jones, T. and Freeman, A.J.B.C. (2016) Rapid, Semi-Automated Fractionation of Freshwater Dissolved Organic Carbon Using DAX 8 (XAD 8) and XAD 4 Resins in Tandem. Natural Science, 8, 487-498. http://dx.doi.org/10.4236/ns.2016.811050

Received: August 19, 2016

Accepted: November 19, 2016

Published: November 22, 2016

Copyright $\odot 2016$ by authors and Scientific Research Publishing Inc. This work is licensed under the Creative Commons Attribution International License (CC BY 4.0).

http://creativecommons.org/licenses/by/4.0/

(c) (i) Open Access

\begin{abstract}
Natural dissolved organic carbon (DOC) consists of different bio-molecular classes of compounds that are currently very difficult and time-consuming to isolate as individual compounds. However, it is possible to separate natural DOC into hydrophobic and hydrophilic fractions. Such characterisation approaches are becoming increasingly important because, over the past 20 years natural DOC concentrations have been rising rapidly in many parts of the world, most likely influenced by climate change. Higher DOC concentrations in drinking water catchments present a serious problem for the water industry because DOC can form disinfection by-products DBPs during water treatment (e.g. chlorination). Hence, there is an urgent need to better characterise natural DOC before, during and after water treatment. However, current DOC fractionation procedures are extremely laborious requiring days and continual manual monitoring to separate sufficient quantities of DOC for subsequent analysis. This seriously limits sample throughput and the parameter space which can be studied. In this paper, we propose a much more rapid semi-automated method (12.5 hours/litre/sample) which utilises readily available equipment, i.e., HPLC pump or similar and sequential columns of Amberlite DAX 8 and XAD 4 resins. The method reduces the manual input from continual attention to minutes. This paper describes the development of the method and its application in the fractionation of natural DOC from reservoir and lake samples fed from upland peat-land catchments. Recoveries are found to be comparable to those using the manual technique, with the dominant component being hydrophobic acid accounting for $35 \%-40 \%$ of the natural DOC with the second largest, being hydrophilic acid at $20 \%-27 \%$.
\end{abstract}

\section{Keywords}

Dissolved Organic Carbon, Hydrophilic Compounds, Hydrophobic Compounds, Fulvic Acids, Humic Acids, Resins 


\section{Introduction}

The world's peatlands occupy $4 \%-6 \%$ of the land mass and hold within them an estimated 450 Giga tons of carbon mostly assimilated from the atmosphere by photosynthesis [1]. These peatlands, especially in Northern Europe are the principal catchments and sources of drinking water for the majority of the population. Recent records show that the DOC concentration in the rivers and lakes derived from these peat-dominated sources has increased by $91 \%$ over the past 15 years and evidence suggests that this trend is being repeated in Europe and North America [2] [3]. Although natural DOC in its natural state does not directly present a health problem, it can influence the water's aesthetic qualities (particularly colour, odour and taste), and potentially it can act as a food source for microbes. However, when it is subjected to the essential disinfection procedures (e.g. chlorination) at a water treatment works, a number of potentially toxic disinfection by-products (DBPs) can be produced such as trihalomethanes (THMs) [4] [5] [6], haloacetonitriles (HANs) [7] and haloacetic acids (HAAs) [8] [9]. These DBPs can have a detrimental effect upon human health [10] [11] [12]. Hence, it is necessary to understand DOC properties and how DBPs are formed to try to limit their occurrence.

DOC in water is operationally defined by the water industry as the fraction of organic matter that passes through a $0.45 \mu \mathrm{m}$ filter. Although this classification has recently been subject to criticism, partly due to the inadequacy of such filters in removing colloidal material, it still remains as the practical definition [13]. DOC consists of two major components; the non-humic and the humic. The non-humic material encompasses a series of biomolecules that include lipids, carbohydrates, polysaccharides, amino acids, waxes and proteins [14] whilst humic substances can be described as naturally occurring, refractory, macromolecular, heterogeneous organics [15]. These can be further sub-divided into three components. Firstly, humic acids are fully solvated when $\mathrm{pH}>2$ but not below and they have relatively high molecular weight (5000 - 500,000 Da). Secondly, fulvic acids are water soluble at any $\mathrm{pH}$ and have smaller molecular weights: 600 to $5000 \mathrm{Da}$. [15]. The third and last component is collectively referred to as "the humins". This is the insoluble portion of DOC which is normally removed either by filtration or flocculation.

However, isolating natural DOC from water and separating it into its sub-components present a number of problems. In part, this arises from the relatively low concentrations of DOC (typically $<10 \mathrm{mg} / \mathrm{L}$ ) which means that large volumes of water need to be processed to recover even small quantities of material, the sheer variety of different molecules highly variable nature of the organic matter and the danger of chemical changes taking place during sample processing. In this context, several techniques have been proposed which have included freeze drying [16], solvent extraction and evaporation techniques [17] [18], reverse osmosis [19] and adsorption techniques using granular activated carbon and various ionic and non-ionic macroporous synthetic resins [20] [21] [22]. Although DOC is efficiently removed by these techniques, recovery of the solutes from the granulated carbon is relatively poor. By comparison, the surface and 
sorption/desorption properties of macroporous synthetic resins (e.g. the Amberlite XAD series) are well understood. Indeed, their performance for the extraction and recovery of DOC from water has been evaluated [23] [24] and applied to river and lake fresh water sources. However, the practical application of using the resins for the fractionation of natural DOC samples can require up to $24 \mathrm{~h}$ of processing time [25] per sample. This is particularly problematic when studying natural DOC because this varies spatially, seasonally, diurnally and with climatic conditions. Hence, to properly understand natural systems significant numbers of samples are usually required. When this is combined with the need to process large volumes (due to the low concentrations of natural DOC) this currently represents a significant limitation to progressing scientific understanding of DOC phenomena.

The objective of this paper is to present the development and testing of a rapid, automated method using both DAX 8 (previously known as XAD 8) and XAD 4 resins in tandem to fractionate freshwater lake and reservoir DOC. The method is based around readily available High Performance Liquid Chromatography (HPLC) equipment; using in-house packed columns and a standard HPLC quaternary pump. The sample flows through the system, the fraction collection and the regeneration of resin material are directed via a series of solenoid valves (Bio-Chem) controlled by relays (K.M.Tronic) which are subject to the tailored computer program.

\section{Experimental}

\section{Resins and Columns}

The DAX 8 resin (Sigma-Aldrich) is a hydrophilic acrylic ester with low ion exchange capacity $\left(10^{-2}\right.$ Mequiv $\left.\mathrm{g}^{-1}\right)$, average pore size of $225 \AA$ and surface area of $160 \mathrm{~m}^{2} \cdot \mathrm{g}^{-1}$. The XAD 4 resin (Sigma-Aldrich) a styrene-divinylbenzene copolymer is highly aromatic and hydrophobic and effectively possesses no ion exchange capacity. The average pore size of XAD 4 is also much smaller at $40 \AA$ whilst the surface area is much larger at $725 \mathrm{~m}^{2} \cdot \mathrm{g}^{-1}$. XAD resins have previously been reported for the successful separation/ removal of fulvic and humic acids from water [23] [24] [25] [26].

Fractionation on these resins takes place via an initial sorption and desorption process. This phenomenon effectively takes place by reversing the attractive influence of the zero point charge (ZPC) of the resin surface, hence desorbing the solute DOC. It is therefore useful to calculate the minimum resin quantity for the DAX 8 and XAD 4 fractionation columns to ensure sufficient sorption sites are available which would otherwise limit DOC recovery. To do this, Equation (1) was re-arranged to give (2) andV was calculated where $V_{0.5 r}$ is the sample volume and $k_{0.5 r}^{\prime}$ is the distribution coefficient of resin sorbed solute versus solute dissolved in water [22].

$$
\begin{aligned}
& \mathrm{V}_{0.5 \mathrm{r}}=2 \mathrm{~V}_{0}\left(1+\mathrm{k}_{0.5 \mathrm{r}}^{\prime}\right) \\
& \mathrm{V}_{0}=\mathrm{V}_{0.5 \mathrm{r}} / 2\left(1+\mathrm{k}_{0.5 \mathrm{r}}^{\prime}\right)
\end{aligned}
$$

e.g., for a 1 litre sample where $k_{0.5 r}^{\prime}$ is $50, V_{0}=9.8 \mathrm{ml}$. Given that the void volume of the resins is ca. 65\% [26] the minimum volume of resin required is $15 \mathrm{~cm}^{3}(9.8 / 0.65)$. 
The tandem column arrangement was prepared using two pristine, blank $250 \mathrm{~mm} \times$ $10 \mathrm{~mm}$ HPLC columns (Sigma-Aldrich). Each column was packed with $25 \mathrm{~cm}^{3}$ of the appropriate resin; i.e. a $40 \%$ resin excess to that required for a 1 litre sample. Each column entrance and exit was then fitted with a $0.2 \mu \mathrm{m}$ frit (Supelco Analytical) and sealed in place with HPLC end fittings.

Prior to column packing, each resin was first washed in $0.1 \mathrm{M} \mathrm{NaOH}_{(\mathrm{aq})}$ for $24 \mathrm{~h}$ after which floating debris was removed by careful decantation. The $\mathrm{NaOH}_{(\mathrm{aq})}$ was then removed and the resin washed with de-ionised water until $\mathrm{pH}$ neutral. The resin beads were then transferred to a $50 \mathrm{ml}$ burette followed by series of alternate washes with methanol (AnaLar) and acetonitrile (AnaLar). After careful rinsing with water to remove any residual solvent, the resins were packed into the HPLC columns as slurries. The DAX 8 and XAD 4 columns were then connected in tandem to a series of flow selection valves using PEEK fittings and tubing (0.030" ID) as shown in Figure 1.

Figure 1 shows that the fractionation system is configured with three eluents; deionised water, $0.1 \mathrm{M} \mathrm{NaOH}_{(\mathrm{aq})}$ and $0.1 \mathrm{M} \mathrm{HCl}_{(\mathrm{aq})}$ and the sample. These are fed via an HPLC pump or similar with the series of valves (Bio-Chem Fluidics) controlled by relays using a simple in house pre-programmed computer method. Four $100 \mathrm{~mL}$ bottles (labelled I,G,F,H) are connected to the configured outlet pipes of the valve systems to collect the hydrophobic acid, hydrophilic acid, hydrophilic base, and hydrophobic base fractions respectively. A $1 \mathrm{~L}$ bottle (labelled J) receives the final effluent (labelled the neutral fraction) during the column loading procedure as described below.

To load the resins with the natural water samples DOC. A typical procedure, requires $1 \mathrm{~L}$ of the water sample to be pumped at $4 \mathrm{~mL} /$ minute through the columns with the effluent collected in bottle J (Neutral fraction). The columns are then rinsed with $50 \mathrm{~mL}$ of deionised water before the valves switch to isolate the DAX 8 column. Then $60 \mathrm{~mL}$ of $0.1 \mathrm{M} \mathrm{NaOH}_{(\mathrm{aq})}$ is passed through this column followed by $40 \mathrm{~mL}$ of deionised water (both at $2 \mathrm{~mL} / \mathrm{min}$ ) to desorb and rinse the hydrophobic acid fraction into $\mathrm{F}$. The process was then repeated using $60 \mathrm{~mL}$ of $0.1 \mathrm{M} \mathrm{HCl}_{(\mathrm{aq})}$ and $40 \mathrm{~mL}$ of deionised water (at $2 \mathrm{~mL} / \mathrm{min}$ ) to desorb and rinse the hydrophobic base fraction into G. The programmed valves then switch to isolate the DAX 8 column and the same procedures are followed; first a $\mathrm{NaOH}_{\text {(aq }} / \mathrm{H}_{2} \mathrm{O}$ rinse to desorb the hydrophilic acid fraction into $\mathrm{H}$ and then a $\mathrm{HCl}_{(\mathrm{aq})} / \mathrm{H}_{2} \mathrm{O}$ rinse to desorb the hydrophilic base fraction into I. After this, the valves re-configure and the DAX 8 and XAD 4 columns are washed in tandem first with de-ionised water $(50 \mathrm{~mL})$ at $2 \mathrm{~mL} / \mathrm{min}$ followed by regeneration by pumping $50 \mathrm{~mL}$ of $0.1 \mathrm{M} \mathrm{HCl}_{(\mathrm{aq})}$ at $2 \mathrm{~mL} / \mathrm{min}$. The system is then ready to fraction the next sample.

\section{Results and Discussion}

\subsection{Measurement of Column Resin Bleed}

To establish and measure any resin bleed before starting the experiment, five $1 \mathrm{~L}$ aliquots of milli $\mathrm{Q}$ water were fractioned in sequence. Each fraction was collected as described using the same method as that of the samples. Their TOC was measured with an Analytical Services Ltd., Thermalox TOC/TN analyser. Standards (0 to $5 \mathrm{mg} \cdot \mathrm{L}^{-1}$ ) of 


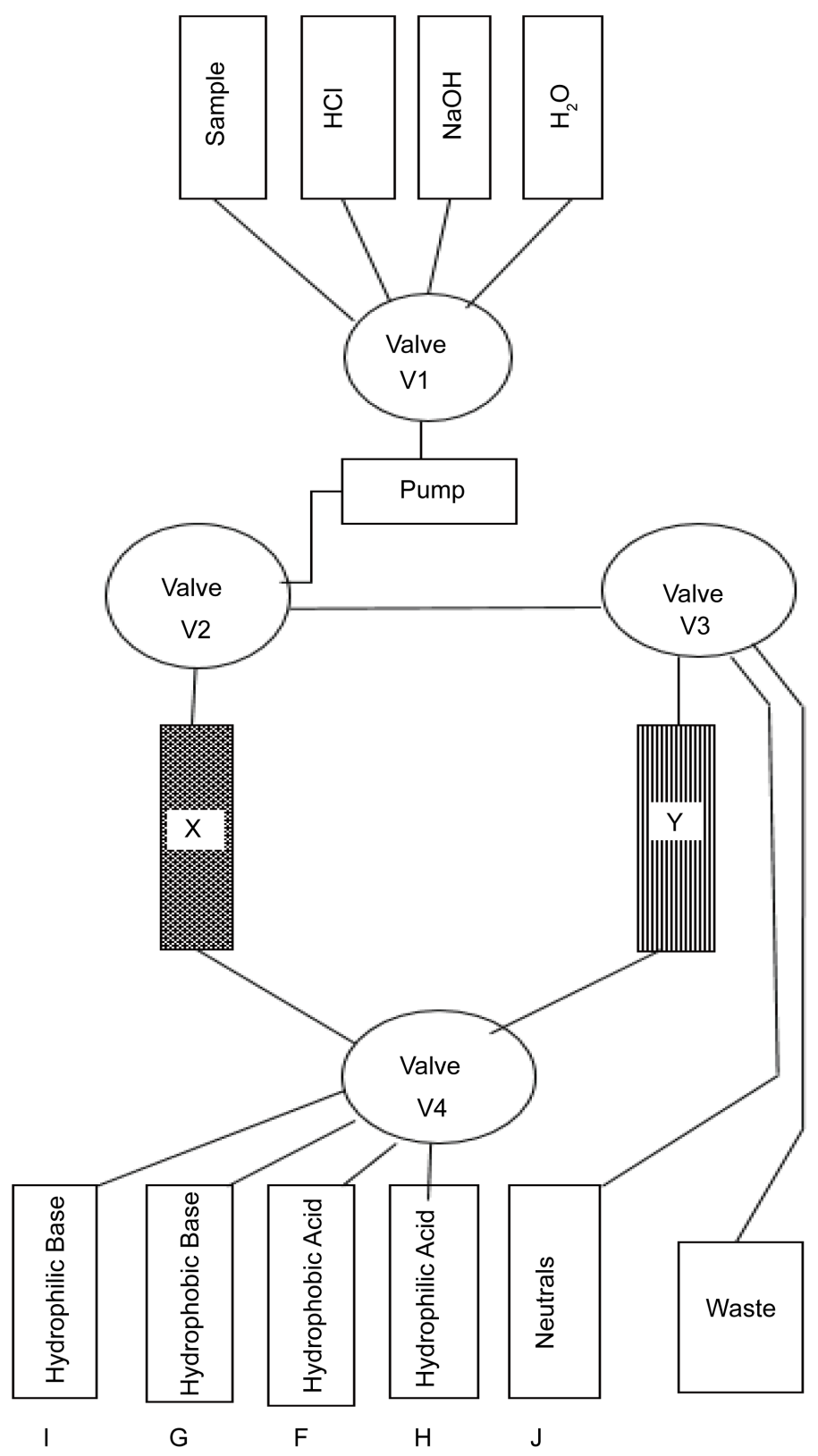

Figure 1. Schematic of the fractionation system (V1-3 = valves $1-3)$.

potassium hydrogen phthalate, AR grade (Lot No F78575AR) were prepared. The data (Table 1) show that there was little evidence of column bleed in any of the fractions and was limited to $<0.3 \mathrm{mg} / \mathrm{L}$ for each sequence of fractions.

\subsection{Natural Water Samples}

Two sets of samples were collected from natural fresh-water sources in February 2012. The 2 sites selected for the exercise were the Cefni and Conwy lakes. Table 2 shows the descriptions of the two sites. Five $1 \mathrm{~L}$ aliquots of each were collected on the same day. Each sample was vacuum filtered through pre-washed Nylon membrane filters $(0.2 \mu \mathrm{m})$ 
Table 1. Mean DOC concentrations desorbed from resins after passing $5 \times 1 \mathrm{~L}$ aliquots of Milli Q water though the tandem DAX 8 and XAD 4 resins using automated fractioning system. The standard deviations are shown in parentheses.

\begin{tabular}{ccc}
\hline Sample & Fraction & Mean DOC (mg/L) \\
\hline & Hydrophobic acid & $0.170(0.025)$ \\
& Hydrophilic acid & $0.150(0.026)$ \\
$1-5$ & Hydrophobic base & $0.040(0.008)$ \\
& Hydrophilic base & $0.030(0.010)$ \\
& Neutrals & $0.270(0.080)$ \\
\hline
\end{tabular}

Table 2. Sample sources, descriptions and typical DOC concentration values.

\begin{tabular}{ccc}
\hline Source & Description & DOC $\left(\mathrm{mg} \cdot \mathrm{l}^{-1}\right)$ \\
\hline Cefni & Man-made reservoir with fen as principal catchment & $6.50 \pm 1.2$ \\
Conwy & Shallow natural upland lake/reservoir within a blanket peat bog & $4.28 \pm 0.4$ \\
\hline
\end{tabular}

within 3 hours of sampling. The $\mathrm{pH}$ of each filtered sample was adjusted to 2.5 with $\mathrm{HCl}_{(\mathrm{aq})}(2 \mathrm{M})$ and stored in darkness at $4^{\circ} \mathrm{C}$.

The stored samples were fractioned using the method and conditions described above.

After collection each of the Hydrophobic and Hydrophilic Acid and Base DOC fractions were diluted to 1 litre with de-ionised milli Q water. The Hydrophobic and Hydrophilic Acid fractions eluted with $0.1 \mathrm{M} \mathrm{NaOH}_{(\mathrm{aq})}$ were $\mathrm{pH}$ adjusted to 2.5 with $2 \mathrm{M}$ $\mathrm{HCl}_{(\mathrm{aq})}$. The DOC concentration of each of these fractions plus the Neutral was then measured to establish the recovery per fraction as a percentage of the total DOC previously measured for the raw un-fractioned samples; the results are shown in Table 3.

Table 4 illustrates the semi-automated method results compared to the manual method results which were collected by loading the columns with sample and eluting the DOC fractions manually using the same eluent and volumes as the semi-automated method.

The data show similar trends (Figure 2) between the two different sites with the Hydrophobic Acid and Neutral fractions showing the highest percentage DOC for all samples. For both sites, the Hydrophobic and Hydrophilic base fractions showed the smallest percentage DOC. The Relative Standard Deviation (RSD) and Standard Deviations (SD) of the data for both series highlights the small spread within the sets with acceptable recoveries that are comparable to ones reported in the literature [22] [25] [27]. The data also demonstrates that the resins operate selectively and that the subsequent \% DOC differences between the Cefni and Conwy hydrophobic acids, hydrophilic acids and neutrals fractions reflect the variable molecular structures that exist within each individual DOC sample series. Table 4 includes the Cefni and Conwy fractionation results for October 2010/11 using the two methods the results are comparable considering that the ratio of the DOC components leaving the catchments may have 
Table 3. \% DOC concentration per fraction of Cefni and Conwy surface water.

\begin{tabular}{ccccccc}
\hline Fraction & \multicolumn{7}{c}{ DOC (\%) } \\
\hline Cefni & S1 & S2 & S3 & S4 & S5 & SD \\
\hline Hydrophobic Acid & 36.6 & 37.2 & 37.9 & 34.3 & 36.6 & 1.3 \\
Hydrophobic Base & 0.8 & 1.1 & 0.8 & 1.2 & 0.8 & 0.2 \\
Hydrophilic Acid & 26.8 & 27.2 & 27.1 & 26.1 & 27.2 & 0.5 \\
Hydrophilic Base & 1.1 & 0.9 & 1.1 & 1.1 & 0.9 & 0.1 \\
Non-retained Neutrals & 29.9 & 19.9 & 28.0 & 27.7 & 28.9 & 4.0 \\
\% Total Recovery & 95.2 & 86.3 & 94.8 & 90.5 & 94.5 & 3.8 \\
Conwy & S1 & S2 & S3 & S4 & S5 & SD \\
Hydrophobic Acid & 38.8 & 40.9 & 38.9 & 38.1 & 37.6 & 1.3 \\
Hydrophobic Base & 0.3 & 0.3 & 0.6 & 0.8 & 0.5 & 0.6 \\
Hydrophilic Acid & 21.3 & 21.1 & 20.3 & 21.3 & 20.1 & 0.2 \\
Hydrophilic Base & 0.9 & 1.1 & 0.9 & 1.2 & 0.9 & 0.1 \\
Non-retained Neutrals & 33.9 & 32.7 & 35.0 & 36.2 & 34.7 & 1.3 \\
\% Total Recovery & 95.2 & 96.1 & 95.7 & 97.6 & 93.8 & 1.4 \\
\hline
\end{tabular}

Table 4. Cefni and Conwy fractions using standard and automated methods. Key: $\dagger=$ standard method and $\ddagger=$ automated method.

\begin{tabular}{|c|c|c|c|c|}
\hline \multirow{3}{*}{ Fraction } & \multicolumn{4}{|c|}{$\operatorname{DOC}(\%)$} \\
\hline & \multicolumn{2}{|c|}{ Cefni } & \multicolumn{2}{|c|}{ Conwy } \\
\hline & Oct $2010 \dagger$ & Oct $2011 \ddagger$ & Oct $2010 \dagger$ & Oct 2011 \\
\hline Hydrophobic Acid & 39.7 & 38.6 & 38.5 & 41.5 \\
\hline Hydrophobic Base & 1.5 & 0.3 & 0.4 & 0.1 \\
\hline Hydrophilic Acid & 22.2 & 25.5 & 27.1 & 23.7 \\
\hline Hydrophilic Base & 1.1 & 0.2 & 0.4 & 0.1 \\
\hline Non- retained Neutrals & 28.6 & 29.6 & 28.4 & 30.0 \\
\hline \% Recovery & 93.1 & 94.2 & 94.9 & 95.1 \\
\hline
\end{tabular}

been subjected to different meteorological conditions.

\section{Discussion}

The combined resin procedure recovers natural DOC relatively simply without the use of contaminating organic solvents or reagents. The sequence of resins is important in part because of the significant difference in pore size and surface area between the resins. This combination of the DAX 8 and XAD 4 resins are believed to recover a large part of the DOC from natural water predominantly through physical processes [26]. The dimension of the pore sizes of the DAX 8 resin facilitate more rapid diffusion of 


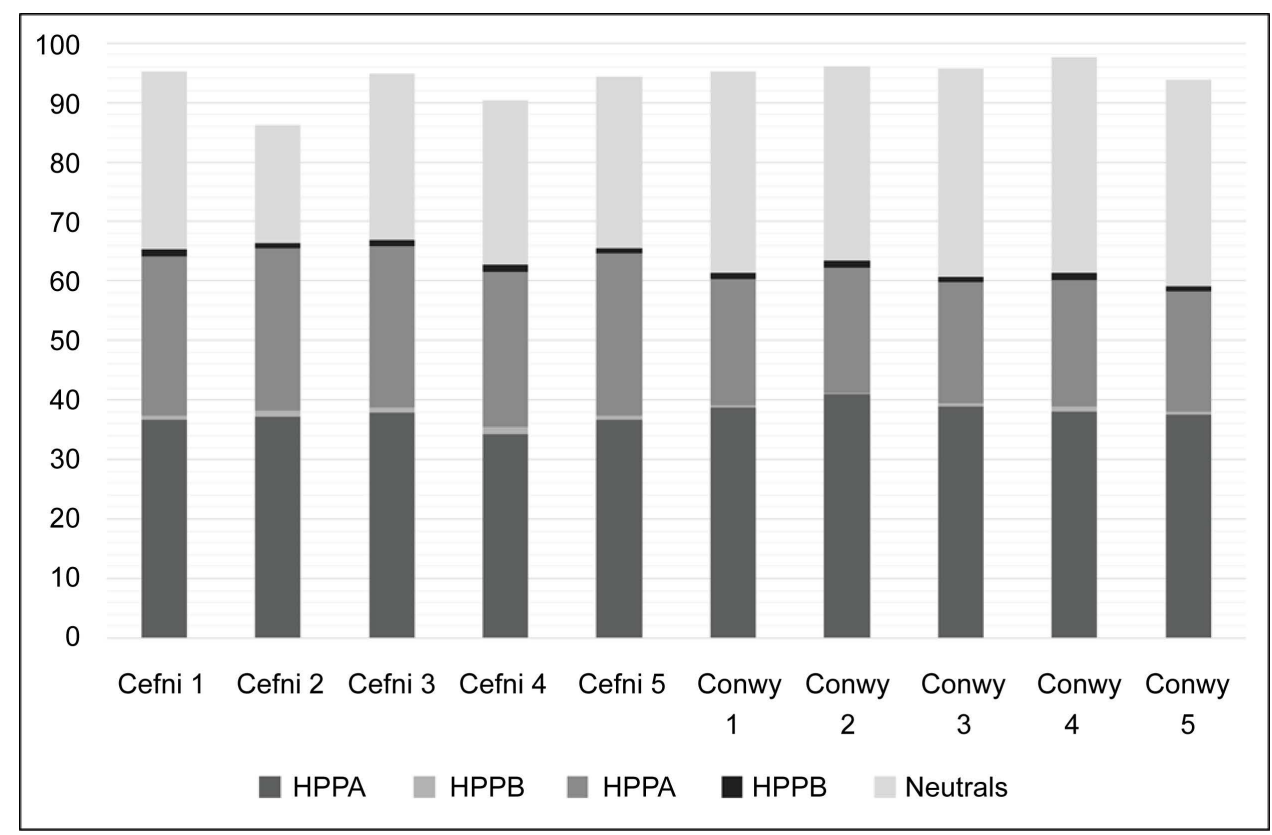

Figure 2. Cefni and Conwy sample fraction distributions (\%).

fulvic and humic acid macromolecules (termed in the literature as the hydrophobic acids) in and out of the pores whilst interacting with the sorption sites held within them. When the hydrophobic acid macromolecules have been sorbed by the DAX 8 , the sample then progresses through the XAD 4 resin. This resin consists of a highly crosslinked surface with a much smaller pore size ( $40 \AA=4 \mathrm{~nm})$. These pores are believed to only allow the diffusion of lower molecular weight solutes, i.e., hydrophilic acids [23]. The molecules which are described in this paper as the Neutrals are believed to exhibit characteristics that do not comply with the properties of the sorption sites of both resins, hence they are not retained.

Each of the samples show the presence of all the different possible fractions. It is interesting to note however that, using the notation of Malcolm et al. [26] these fractions are labelled as Hydrophilic or Hydrophobic acids or bases, or as the non-retained neutral fraction for the DOC passing all the way through all the columns. However, chromatographic separations are normally achieved by matching the functional groups of the column stationary phase with those of the target analytes; a "like-with-like" approach. This method is used so that the partition coefficients are optimised for different components of a mixture. Ideally, this should result in different components of a mixture spending differing amounts of time associated either with the stationary or mobile phases resulting in different partition coefficients and hence different retention times. However, the aim of using these two resins here is not to carry out a "normal" chromatographic separation but rather to group together broadly similar components of a complex, naturally-occurring mixture by sorbing and retaining them on the resin. In reality, the first resin (DAX 8) is actually more hydrophilic than the second (XAD 4) and yet counter-intuitively, in this system, it is considered to retain the Hydrophobic 
acids and bases. The reasoning here is that the much larger pore size (225 $\AA$ ) of the DAX 8 is sufficient to allow much larger molecular weight (MW) DOC to diffuse into the pores and sorb. This fraction is labelled Hydrophobic Acids and Bases because the higher MW is expected to contain more aromatic functionality. Once the high MW DOC material is inside the pores, the DAX 8 resin is believed to act in a similar manner to a solid phase extraction resin. By comparison, the much smaller pore size of the XAD 4 resin ( $40 \AA$ ) only allows much lower MW DOC to diffuse in and sorb. This material is expected to contain less aromatic character and so is defined as Hydrophylic Acids and Bases.

Considering the DOC data for the fractions for the two sites in the above context; although there are differing relative concentrations within the acid, base and neutral classifications the subtle differences between sites can be determined. This supports the fact that rapid fractionation can be successfully achieved and the development of the method described here has significantly reduced the time and tedious work [13] required to fractionate samples. The classical method uses resins packed into glass columns and a peristaltic pump and is both labour intensive and time consuming. Here, using a combination of relay controlled solenoid valves, HPLC pump and HPLC packed columns, controlled with a tailored program, the time has been reduced to approximately 8 hours for complete sample fractionation into its individual components, without intervention at any point in the exercise. A breakdown of the time employed to carry out the task includes $4.2 \mathrm{~h}$ to pass a $1 \mathrm{~L}$ sample through the columns in tandem. Desorption of both columns requires $3.33 \mathrm{~h}$, followed by washing and re-generation requiring a further $0.8 \mathrm{~h}$. The time periods may be adjusted to accommodate different sample volumes, i.e., loading flow rates, desorption flow rates, resins and resin volumes. The manual method time breakdown requires a period of $8.4 \mathrm{~h}$ to load the sample onto the columns, followed by $1.7 \mathrm{~h}$ desorption time per column. Preparation of both columns for the next fractionation requires $0.8 \mathrm{~h}$ per column. Thus the time for the fractionation of one sample is $13.4 \mathrm{~h}$ with high levels of monitoring. Hence, one sample using the manual method requires approximately two working days compared to the automated which could fraction approximately 5 - 6 samples.

\section{Conclusion}

The results show that collecting data using an automated resin-based fractionation system is less time-consuming and labour-intensive than a manual system (by a factor by five to six times). The data also show that recoveries from replicate samples of ca. 95\% for the automated samples are comparable (and very slightly better) than those achieved using the manual method. Comparing the data between the individual fractions, the "acidic" fractions show the larger \%DOC and these are within $2 \%$ between the 2 methods. By comparison, the much smaller \%DOC observed in the hydrophilic and hydrophobic base fractions are slightly lower for the automated method. However, the trends between the fractions are broadly similar which support the use of this method to study DOC. This is important for a range of possible end uses but is particularly 
relevant in the context of water treatment because upland peatlands are known to be exporting increasing concentrations of DOC as a result of climate change. As this is likely to be an increasing influence, the study of peatland DOC will be increasingly important because these provide an important source of potable water. Characterising this natural DOC has proved both time-consuming and frustratingly difficult for many years. This hinders the understanding of water potable water disinfection using chlorination which is important because this produces disinfection by-products (DBPs), the main examples being trihalomethanes (THMs). Thus, automating DOC fractionation should enable both faster sample turnaround and increased throughput. This will enable far greater numbers of samples to be studied at different sites and diurnally and seasonally using the manual procedures. Site specific influences (e.g. geology, hydrology, fauna and temporal changes) are known to strongly influence DOC concentration, fractionation and trihalomethane formation potential [28] [29] [30]. Furthermore, the technique may be used to study other water treatment plant effects upon DOC; for example ozonation, filtration, coagulation [31] [32], membrane fouling and UV photolysis etc. In turn, this will help support the continuing efforts of water companies to meet the demands of the regulatory authorities to limit THM concentrations in drinking water [33].

\section{Acknowledgements}

We gratefully thank NERC, DwrCymru/Welsh Water and project funding under the $1^{\text {st }}$ call of ERA-ENVHEALTH. CSA Coordination Action. Grant agreement 219337 EP7ENV-2007-CSA-1.2.3-01, Caroline Shultz of the University of Berlin (3 month student placement).

\section{References}

[1] Gorham, E. (1991) Northern Peatlands: Role in the Carbon Cycle and Probable Responses to Climatic Warming. Ecological Applications, 1, 182-195.

http://dx.doi.org/10.2307/1941811

[2] Freeman, C., Ostle, N.J., Fenner, N., Kang, H., Dowrick, D.J., Reynolds, B., Lock, M.A., Sleep, D., Hughes, S. and Hudson, J. (2004) Export of Dissolved Organic Carbon from Peatlands under Elevated Carbon Dioxide Levels. Nature, 430, 195-198. http://dx.doi.org/10.1038/nature02707

[3] Evans, C.D., Chapman, P.J., Clark, J.M., Monteith, D.T. and Cressers, C. (2006) Alternative Explanations for Rising Dissolved Organic Carbon Export from Organic Soils. Global Change Biology, 12, 2044-2053. http://dx.doi.org/10.1111/j.1365-2486.2006.01241.x

[4] Rook, J.J. (1977) Chlorination Reactions of Fulvic Acids in Natural Waters. Environmental Science \& Technology, 11, 478-482. http://dx.doi.org/10.1021/es60128a014

[5] Hirose, Y. and Okitsu, T. (1982) Formation of Trihalomethanes by Reaction of Halogenated Phenols or Halogenated Anilines with Sodium Hypochlorite. Chemosphere, 11, 81-87. http://dx.doi.org/10.1016/0045-6535(82)90096-0

[6] Sánchez, M.C., Pedraza Domínguez, A. and CachazaSilverio, J.M. (1993) Reaction Kinetics of Humic Acid with Sodium Hypochlorite. Water Research, 27, 815-820. http://dx.doi.org/10.1016/0043-1354(93)90145-8 
[7] Shah, A.D., Dotson, A.D., Linden, K.G. and Mitch, W.A. (2011) Impact of UV Disinfection Combined with Chlorination/Chloramination on the Formation of Halonitromethanes and Haloacetonitriles in Drinking Water. Environmental Science \& Technology, 45, 3657-3664. http://dx.doi.org/10.1021/es104240v

[8] Chen, C.-Y., Chang, S.-N. and Wang, G-S. (2009) Determination of Ten Haloacetic Acids in Drinking Water Using High-Performance and Ultra-Performance Liquid Chromatography-Tandem Mass Spectrometry. Journal of Chromatographic Science, 47, 67-74. http://dx.doi.org/10.1093/chromsci/47.1.67

[9] Al-Shatri, M.A., Nuhu, A.A. and Basheer, C. (2014) Determination of Haloacetic Acids in Bottled and Tap Water Sources by Dispersive Liquid-Liquid Microextraction and GC-MS Analysis. The Scientific World Journal, Article ID: 695049.

[10] Bull, R.J., Meier, J.R., Robinson, M., Ringhand, H.P., Laurie, R.D. and Stober, J.A. (1985) Evaluation of Mutagenic and Carcinogenic Properties of Brominated and Chlorinated Acetonitriles: By-Products of Chlorination. Fundamental and Applied Toxicology, 5, 10651074. http://dx.doi.org/10.1016/0272-0590(85)90142-3

[11] Daniel, F.B., Schenck, K.M., Mattox, J.K., Lin, E.L.C., Haas, D.L. and Pereira, M.A. (1986) Genotoxic Properties of Haloacetonitriles: Drinking Water By-Products of Chlorine Disinfection. Fundamental and Applied Toxicology, 6, 447-453. http://dx.doi.org/10.1016/0272-0590(86)90218-6

[12] Porter, C.K., Putnam, S.D., Hunting, K.L. and Riddle, M.R. (2005) The Effect of Trihalomethane and Haloacetic Acid Exposure on Fetal Growth in a Maryland County. American Journal of Epidemiology, 162, 334-344. http://dx.doi.org/10.1093/aje/kwi211

[13] McDonald, S., Bishop, A.G., Prenzler, P.D. and Robards, K. (2004) Analytical Chemistry of Freshwater Humic Substances. Analytica Chimica Acta, 527, 105-124. http://dx.doi.org/10.1016/j.aca.2004.10.011

[14] Piccolo, A. (2001) The Supramolecular Structure of Humic Substances. Soil Science, 166, 810-832.

[15] MacCarthy, R.L., Malcolm, C.E., Clapp, P.R. and Bloom, P.R., Eds. (1990) Composition of Humin in Stream Sediments and Peat. In: Humic Substances in Soil and Crop Sciences, Soil Science Society of America, Madison, USA.

[16] Shapiro, J. (1961) Freezing-Out, a Safe Technique for Concentration of Dilute Solutions. Science, 133, 2063-2064. http://dx.doi.org/10.1126/science.133.3470.2063

[17] National Academy of Sciences (1977) Organic Solutes. In: Drinking Water and Health, National Academy of Sciences, Washington DC, 489-856.

[18] Wu, C. and Suffet, I.H. (1977) Table of Contents. Analytical Chemistry, 49, 463-466. http://dx.doi.org/10.1021/ac50014a703

[19] Deinzer, M., Meltin, R. and Mitchell, D. (1975) Trace Organic Contaminants in Drinking Watert-Their Concentration by Reverse Osmosis. Water Resources Research, 9, 799-805.

[20] Mantoura, R.F.C. and Riley, J.P. (1975) The Analytical Concentration of Humic Substances from Natural Waters. Analytica Chimica Acta, 76, 97-106. http://dx.doi.org/10.1016/S0003-2670(01)81990-5

[21] Thurman, E.M. and Malcolm, R.L. (1981) Preparative Isolation of Aquatic Humic Substances. Environmental Science \& Technology, 15, 463-466. http://dx.doi.org/10.1021/es00086a012

[22] Leenheer, J.A. (1981) Comprehensive Approach to Preparative Isolation and Fractionation of Dissolved Organic Carbon from Natural Waters and Wastewaters. Environmental Science \& Technology, 15, 578-587. http://dx.doi.org/10.1021/es00087a010 
[23] Aiken, G.R., Thurman, E.M., Malcolm, R.L. and Walton, H.F. (1979) Comparison of XAD Macroporous Resins for the Concentration of Fulvic Acid from Aqueous Solution. Analytical Chemistry, 51, 1799-1803. http://dx.doi.org/10.1021/ac50047a044

[24] Junk, G.A., Richard, J.J., Grieser, M.D., Witiak, D., Witiak, J.L., Arguello, M.C., Vick, R., Svec, H.J., Fritz, J.S. and Calder, G.V. (1974) Use of Macroreticular Resins in the Analysis of Water for Trace Organic Contaminants. Journal of Chromatography A, 99, 745-762. http://dx.doi.org/10.1016/S0021-9673(00)90900-2

[25] Ratpukdi, T., Rice, J.A., Chilom, G., Bezbaruah, A. and Khan, E. (2009) Rapid Fractionation of Natural Organic Matter in Water Using a Novel Solid-Phase Extraction Technique. Water Environment Research, 81, 2299-2308. http://dx.doi.org/10.2175/106143009X407302

[26] Malcolm, R.L. and MacCarthy, P. (1992) Quantitative Evaluation of XAD-8 and XAD-4 Resins Used in Tandem for Removing Organic Solutes from Water. Environment International, 18, 597-607. http://dx.doi.org/10.1016/0160-4120(92)90027-2

[27] Wei, Q., Wang, D., Wei, Q., Qiao, C., Shi, B. and Tang, H. (2007) Size and Resin Fractionations of Dissolved Organic Matter and Trihalomethane Precursors from Four Typical Source Waters in China. Environmental Monitoring and Assessment, 141, 347-357. http://dx.doi.org/10.1007/s10661-007-9901-1

[28] Gough, R., Holliman, P.J., Willis, N., Jones, T.G. and Freeman, C. (2012) Influence of Habitat on the Quantity and Composition of Leachable Carbon in the $\mathrm{O}_{2}$ Horizon: Potential Implications for Potable Water Treatment. Lake and Reservoir Management, 28, 282-292. http://dx.doi.org/10.1080/07438141.2012.741187

[29] Hughes, D.D., Holliman, P.J., Jones, T. and Freeman, C. (2013) Temporal Variations in Dissolved Organic Carbon Concentrations in Upland and Lowland Lakes in North Wales. Water and Environment Journal, 27, 275-283. http://dx.doi.org/10.1111/wej.12025

[30] Gough, R., Holliman, P.J., Cooke, G.M. and Freeman, C. (2015) Characterisation of Algogenic Organic Matter during an Algal Bloom and Its Implications for Trihalomethane Formation. Sustainability of Water Quality and Ecology, 6, 11-19. http://dx.doi.org/10.1016/j.swaqe.2014.12.008

[31] Gough, R. Holliman, P.J., Heard, T.R. and Freeman, C. (2014) Dissolved Organic Carbon and Trihalomethane Formation Potential Removal during Coagulation of a Typical UK Upland Water with Alum, PAX-18 and PIX-322. Journal of Water Supply: Research and Technology-AQUA, 63, 650-660. http://dx.doi.org/10.2166/aqua.2014.007

[32] Gough, R., Holliman, P.J., Willis, N. and Freeman, C. (2014) Dissolved Organic Carbon and Trihalomethane Precursor Removal at a UK Upland Water Treatment Works. Science of The Total Environment, 468-469, 228-239. http://dx.doi.org/10.1016/j.scitotenv.2013.08.048

[33] UK Govt. (2000) The Water Supply (Quality) Regulations 2000. 
Submit or recommend next manuscript to SCIRP and we will provide best service for you:

Accepting pre-submission inquiries through Email, Facebook, LinkedIn, Twitter, etc.

A wide selection of journals (inclusive of 9 subjects, more than 200 journals)

Providing 24-hour high-quality service

User-friendly online submission system

Fair and swift peer-review system

Efficient typesetting and proofreading procedure

Display of the result of downloads and visits, as well as the number of cited articles

Maximum dissemination of your research work

Submit your manuscript at: http://papersubmission.scirp.org/

Or contact ns@scirp.org 